\title{
The Effect of Quantitative Feed Restriction Duration on Growth Performance and Carcass Characteristics of Broiler Chickens
}

\author{
Ziphozihle Gobane ${ }^{1}$, Sindisile Goni2 ${ }^{*}$, Denice Chikwanda ${ }^{1}$, Leocadia Zhou ${ }^{3}$ \\ ${ }^{1}$ Department of Livestock and Pasture Science, University of Fort Hare, Alice, South Africa \\ ${ }^{2}$ Döhne Agricultural Development Institute, Stutterheim, South Africa \\ ${ }^{3}$ Risk and Vulnerability Science Centre, Faculty of Science \& Agriculture, University of Fort Hare, Alice, South Africa \\ Email: *sindisilegoni@gmail.com
}

How to cite this paper: Gobane, Z., Goni, S., Chikwanda, D. and Zhou, L. (2021) The Effect of Quantitative Feed Restriction Duration on Growth Performance and Carcass Characteristics of Broiler Chickens. Open Journal of Animal Sciences, 11, 635-645. https://doi.org/10.4236/ojas.2021.114043

Received: July 29, 2021

Accepted: September 27, 2021

Published: September 30, 2021

Copyright (c) 2021 by author(s) and Scientific Research Publishing Inc. This work is licensed under the Creative Commons Attribution International License (CC BY 4.0).

http://creativecommons.org/licenses/by/4.0/

\begin{abstract}
The growth productivity of broilers is influenced by improving growth performance through improving body weight, average daily gain, and feed conversion rate. The objective of the study was to determine the effect of quantitative feed restriction duration on growth performance and carcass characteristics of broilers. A total of 144 day-old broiler chicks were reared in a deep litter system until slaughter at 42 days. Chicks were randomly allocated to three treatments which were replicated three times with 16 birds per replicate. The three treatments were the control (T1), one week of feed restriction (T2), and two weeks of feed restriction (T3). Birds were fed with starter, grower and finisher diets. The average daily gain (ADG), average daily feed intake (ADFI), and the feed conversion ratio (FCR) were computed for each week. Carcass weight and internal organs weights were measured. The body weight gained by the birds in $\mathrm{T} 1$ was similar to the birds that were restricted for a week. The treatments had a significant effect on the average daily gain in weeks 4,5 , and 6 . The ADG for T2 was higher $(\mathrm{P}<0.05)$ at week 5 after 1 week of restriction, than $\mathrm{T} 1$ and $\mathrm{T} 3$. The feed conversion ratio was significantly higher in T3 after 2 weeks of restriction. In T2 and T3, feed intake was significantly lower than in birds fed ad libitum at week 4 at the start of the treatment. There was no significant effect on the relative weights of heart weights, liver, gizzard, feet, and heads among the treatment groups except for intestine weight which was lower $(\mathrm{P}<0.05)$ in $\mathrm{T} 1$ than $\mathrm{T} 2$ and $\mathrm{T} 3$. It was concluded that broilers that were restricted for one week had a positive result in growth performance. Feed restriction had minimal effect on the organ weights of broiler chickens.
\end{abstract}




\section{Keywords}

Average Daily Gain, Body Weight Gain, Broilers, Feed Conversion Ratio, Feed Restriction, Duration

\section{Introduction}

The growth productivity of broilers is influenced by improving growth performance: body weight (BW), average daily gain (ADG) and feed conversion rate (FCR). The FCR is a major factor in reducing production costs and improving the broilers' growth effectiveness. Feed cost represents about $70 \%$ of the cost of producing broilers [1]. The benefits of feed restriction are the monetary savings from raising feed conversion [2]. The main reason for controlling feed intake in broilers is to prevent wastage of feed. Furthermore, to address the issue of high mortality, body fat deposition, high incidence of metabolic diseases and skeletal disorders many strategies have been put forward, including feed restriction.

Feed restriction protocols, including physically declining access to the feed and water during certain times of the day, use the concept of catch-up growth or compensatory growth, with its success depending on the duration of feed restriction. Feed restriction suppresses growth during the restriction period, but the growth reduced can be compensated with greater future intake [3]. Negative effects of feed restriction include chronic hunger, and feeding frustration, increased aggression and over-drinking [4]. Negative physiological effects include adrenal hypertrophy and persistent increases in corticosterone secretion after $24 \mathrm{~h}$ restriction or feed-off days or increased susceptibility to Staphylococcus aureus after $48 \mathrm{~h}$ [5].

Feed restriction provides the opportunity to take advantage of compensatory growth. Compensatory growth refers to the period of rapid growth, relative to age, exhibited by mammals and birds after a period of nutritional restriction. The factors most critical to compensatory growth include the age at which the restriction is applied, the sex and genotype of the animal, the length and severity of the restriction, the quality and length of re-feeding of the re-alimentation diet [6]. Compensatory growth can be accomplished when birds divert more energy towards growth [7].

Feed restriction has been commonly used to optimize lean carcass tissue, reduce metabolic disorders, control body weight, and reduce reproductive problems in both meat-type and egg-type chickens and excessive fat deposition [8]. Excessive fat is one of the main problems faced by the broiler industry resulting in a negative perception of the meat by health conscious consumers. Carcass characteristics are important factors to consider when evaluating alternative feeding programs [9]. Through restricting broiler chickens, there is a relative enlargement of digestive organs, especially the gizzard, crop, pancreas and liver which improve feed intake [8]. Internal organs are significantly affected by restriction, and during the re-alimentation period the stomach growth rapidly and 
the other organs except for the kidneys [10]. Feed restriction has been studied to improve economical and biological performances. Against the aforementioned background, the objective of this study was to determine the effect of quantitative feed restriction duration on growth performance and carcass characteristics of broilers.

\section{Materials and Methods}

\subsection{Study Site}

The study was conducted at the University of Fort Hare which is based in Alice, in the Eastern Cape Province of South Africa (Figure 1).

The site is situated $520 \mathrm{~m}$ above sea level and is located $32.48^{\circ} \mathrm{S}$ and $26.53^{\circ} \mathrm{E}$. The average annual rainfall is approximately $480 \mathrm{~mm}$, and mostly comes in summer. The average mean annual temperature of the farm is $18.7^{\circ} \mathrm{C}$. The topography of the area is generally flat with a few steep slopes.

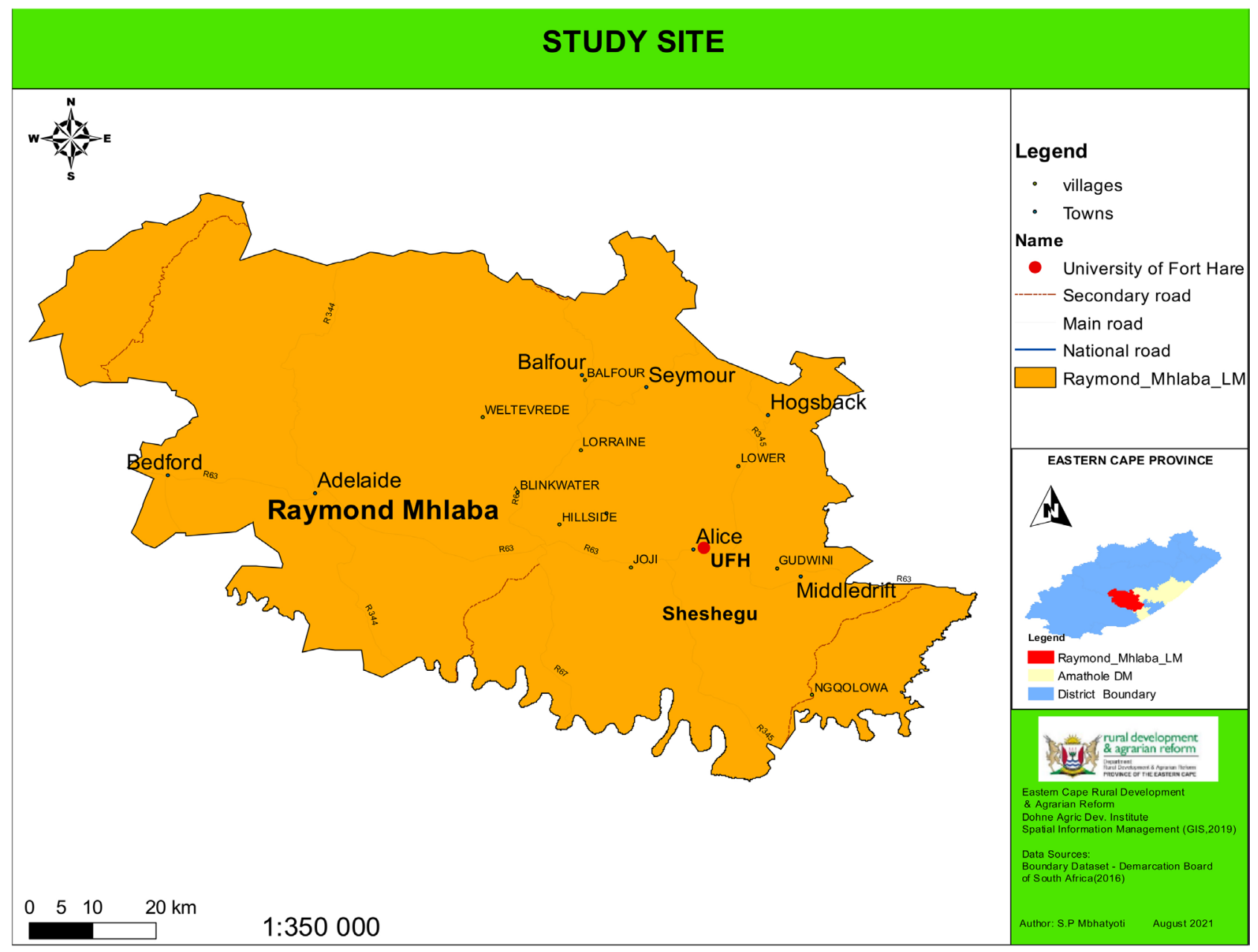

Figure 1. Map showing location of the study site.

\subsection{Feed Restriction Treatments}

A total of 144 day-old broiler chicks were purchased from Umthiza Agricultural 
Co-operation located in Alice town in the Eastern Cape Province, South Africa. All the chicks were managed in one brooding house for the first 21days. On day 22 , the chicks were randomly allocated to three treatments; the control (T1), one week of feed restriction (T2), and two weeks of feed restriction (T3), and three broiler houses were sub-divided into three compartments each. The birds were randomly allocated to each of the nine compartments. Each treatment was replicated three times with 16 birds per compartment being fed as a group and each bird was regarded as the experimental unit. The stocking density was 16 broiler/m2 in all the treatments. Lights were provided throughout the study; infrared lamps were removed after two weeks. All the birds were housed in a low-cost housing unit, where ventilation and temperature were not artificially controlled. Treatment 1 group was fed ad libitum with constant access to the water, for T2 birds were deprived of feed from $19 \mathrm{~h} 00$ until $07 \mathrm{~h} 00$ and from the $22^{\text {nd }}$ to the $28^{\text {th }}$ day, and in the T3 birds were deprived feed from $19 \mathrm{~h} 00$ until $07 \mathrm{~h} 00$ and from the $22^{\text {nd }}$ to the $35^{\text {th }}$ day. The feed consumed by each bird was measured weekly.

\subsection{Management of Birds}

Day old-chicks were placed in the brooding house, offered water with stress pack immediately on arrival and feed was provided two hours later. They were kept in the brooding house for 21 days before they are allocated to their respective treatment groups. All the birds were housed in a low-cost housing unit, where ventilation and temperatures were not artificially controlled. Infrared lights were used to provide heat during the brooding period from day-old until the second week of age. Feed was supplied continuously by constantly topping up the empty feeding troughs. Feed wastages were minimized by filling the feeding troughs to about three-quarters full. Birds were fed with broiler starter (Table 1), from day-old until day 21, grower feed from day 22 until day 35, and broiler finisher from day 36 up until day 42 .

Table 1. Feed specification of the three phase diet that was fed to chickens.

\begin{tabular}{cccc}
\hline Nutrients $(\mathbf{g} / \mathrm{kg})$ & Starter & Grower & Finisher \\
\hline Protein (minimum) & 190 & 170 & 160 \\
Total Lysine (minimum) & 12 & 9 & 9 \\
Total Methionine (minimum) & 5 & 4 & 4 \\
Moisture (maximum) & 120 & 120 & 120 \\
Fat (minimum) & 25 & 25 & 25 \\
Fibre (maximum) & 50 & 70 & 70 \\
Calcium (minimum) & 8 & 8 & 7 \\
Calcium (minimum) & 12 & 12 & 12 \\
Phosphorus (minimum) & 6 & 5 & 5
\end{tabular}

Epol feed manufacture. 


\subsection{Measuring Growth Performance}

One bird was regarded as the experimental unit, chicks were weighed and feed measured weekly according to the replicates numbers using a normal scale. Body weight gain (BWG), average daily feed intake (ADFI), average daily gain (ADG) and feed conversion efficiency (FCE) of the chicks were recorded at the beginning of each week, starting from placement until slaughter. Body weight gain was determined by subtracting the final body weight $(\mathrm{g})$ from the initial body weight (g); average daily gain (ADG) is equal to week 2 weight - week 1 weight/ number of days between; feed conversion efficiency (FCE) by dividing average feed intake ( $\mathrm{g}$ ) by the average body weights ( $\mathrm{g}$ ); and average daily feed intake (ADFI) was determined by subtracting given feed (g/day) from the remaining feed (g/day).

\subsection{Slaughter Procedure, Carcass \& Organ Weights Measurement}

One bird from each replicate was selected randomly at the end of the experiment to measure the meat yield and carcass characteristics of the chickens. The selected birds were starved of feed and water over night for 12 hours. Before slaughtering, the individual weight of the birds was recorded. Slaughtering was done following the normal procedures of the abattoir, where they were first stunned with an electrical stunner (50 - 70 volts) under the beak for 5 seconds to reduce unconsciousness before slaughter. The unconscious chickens were then attached by their legs onto a conveyor line. While hanging, the throats were cut using a sharp knife, only one person was responsible for the throat cutting and one person for stunning. While they were hanged, chickens were given plenty of time to bleed. After plucking the feathers, the fully dressed weights of the carcasses were taken and recorded, and carcasses were then separated into breast, thigh, feet, head and the internal organs (viscera). The cuts were individually weighed and the weights were expressed as percentages of the live weight of the carcass. Dressing percentage was calculated as proportion of carcass weight to live weight of each bird.

\subsection{Statistical Analysis}

The BWG, ADFI, ADG, FCE and the carcass characteristics (slaughter weight, carcass weight, dressing percentage) and intestinal organs (liver weight, heart weight, gizzard weight) were analysed using one-way analysis of variance (ANOVA) [11]. The least significant difference (LSD) method was used to compare the means. The following model was adopted for the traits measured:

$$
Y_{i j}=\mu+B_{i}+T_{j}+e_{i j}
$$

where: $Y_{i j}$ is an observation for each trait, $\mu$ is the population mean, $B_{i}$ is the effect of the $i^{\text {th }}$ week, $T_{j}$ is the effect of the $j^{\text {th }}$ treatments, and $e_{i j}$ is the random error. 


\section{Results and Discussion}

The effect of quantitative feed restriction on body weight gain during feeding broiler chicken is presented in Figure 2. The lowest body weight gain was observed from the birds in T3 which were kept under two weeks of feed restriction and had one week of sustaining before slaughter. These results concur with [12] and [13] who observed reduced weight gain in restricted broilers compared to those of full-fed control birds. On the other hand, these results are not in accordance with those of [14] [15] and [16], who observed no differences in weight gain in feed restricted and ad libitum fed birds. The T2 birds which were restricted for one week compensated and reached the same weight as the unrestricted birds at weeks 5 and 6 . Therefore, this implies that the period of restriction did not affect $(\mathrm{P}>0.05)$ the market body weight and similar results were observed in several studies [17] [18] [19]. The T3 groups were unable to totally compensate for the loss of weight gain during the restriction period. Similar findings by [20] and [21] also showed that there was not a complete body weight recovery after feed restriction in chickens with a longer period. [22] also observed and considered that full body weight recovery could be more consistent if short restriction periods were used instead of the long ones.

The effect of feed restriction on average daily gain of broiler chicken is presented in Table 2. The treatments had a significant effect on the average daily gain in weeks 4,5 and 6 . Feed restriction for T3 was reduced $(\mathrm{P}<0.05)$ on the ADG of broiler chicken at week 4 . Treatment 3 group had lower ADG than other treatments after feed restriction period in week 5. Similar results in weight gain were reported by [22] and [23] when broilers were fed with quantitative feeding from day 1 until day 14 of age. The T3 broiler chickens had higher $(\mathrm{P}<0.05)$

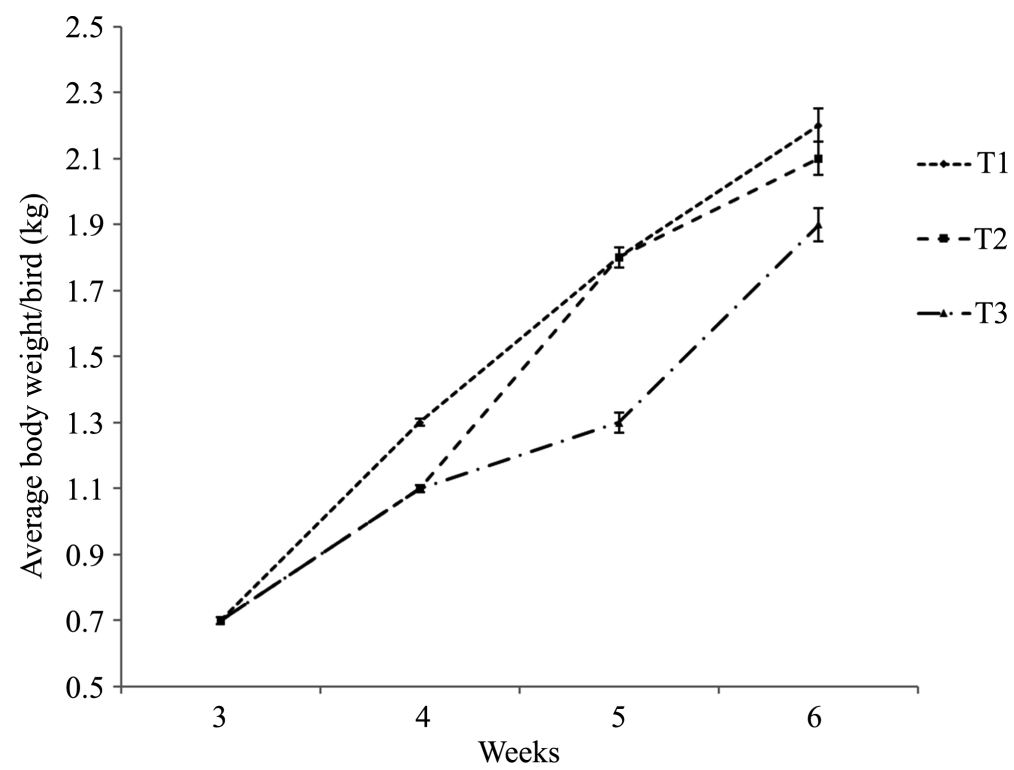

Figure 2. Growth curves of birds exposed to different feed restriction durations T1-birds fed ad libitum, T2-birds restricted of feed for one week, T3-birds restricted of feed for two weeks. 
Table 2. Least square means and standard errors of average daily gain of birds subjected to control, one week and two weeks of feed restriction treatments from week three until six weeks of age.

\begin{tabular}{cccc}
\hline & \multicolumn{3}{c}{ Treatments (T) } \\
\cline { 2 - 4 } ADG in weeks (ADG W) & $\begin{array}{c}\mathrm{T} 1 \\
\text { (Control) }\end{array}$ & $\begin{array}{c}\text { T2 } \\
\text { (One week) }\end{array}$ & $\begin{array}{c}\text { T3 } \\
\text { (Two weeks) }\end{array}$ \\
\hline ADG W3 (g/bird/day) & $57.4 \pm 4.67$ & $55.7 .4 \pm 4.59$ & $60.9 \pm 4.75$ \\
ADG W4 (g/bird/day) & $87.1^{\mathrm{b}} \pm 4.67$ & $57.6^{\mathrm{a}} \pm 4.67$ & $53.4^{\mathrm{a}} \pm 4.67$ \\
ADG W5 (g/bird/day) & $78.5^{\mathrm{b}} \pm 4.67$ & $102.9^{\mathrm{c}} \pm 4.67$ & $36.0^{\mathrm{a}} \pm 5.11$ \\
ADG W6 (g/bird/day) & $60.9^{\mathrm{b}} \pm 4.67$ & $44.3^{\mathrm{a}} \pm 4.75$ & $93.5^{\mathrm{c}} \pm 4.75$ \\
\hline
\end{tabular}

Means in the same row with different superscripts are significantly different $(\mathrm{P}<0.05)$ from each other.

Table 3. Least square means and standard errors of feed conversion efficiency of birds subjected to control, one week and two weeks of feed restriction treatments from week three until six weeks of age.

\begin{tabular}{cccc}
\hline & \multicolumn{3}{c}{ Treatments (T) } \\
\cline { 2 - 4 } FCE in weeks (FCE W) & $\begin{array}{c}\mathrm{T} 1 \\
\text { (Control) }\end{array}$ & $\begin{array}{c}\mathrm{T} 2 \\
\text { (One week) }\end{array}$ & $\begin{array}{c}\text { T3 } \\
\text { (Two weeks) }\end{array}$ \\
\hline FCE W3 (g/bird/day) & $1.84 \pm 0.11$ & $1.81 \pm 0.11$ & $1.70 \pm 0.12$ \\
FCE W4 (g/bird/day) & $0.57^{\mathrm{a}} \pm 0.11$ & $0.73^{\mathrm{b}} \pm 0.11$ & $0.69^{\mathrm{c}} \pm 0.11$ \\
FCE W5 (g/bird/day) & $0.74^{\mathrm{a}} \pm 0.11$ & $0.53^{\mathrm{a}} \pm 0.11$ & $1.51^{\mathrm{b}} \pm 0.13$ \\
FCE W6 (g/bird/day) & $1.55^{\mathrm{b}} \pm 0.11$ & $1.83^{\mathrm{b}} \pm 0.12$ & $0.8^{\mathrm{a}} \pm 0.12$ \\
\hline
\end{tabular}

Means in the same row with different superscripts are significantly different $(\mathrm{P}<0.05)$ from each other.

ADG than other groups at week 6; T2 had high ADG at week 5. A study by [24], postulated that the accelerated growth rate might be associated with relatively lower overall maintenance energy needs in feed restricted chickens compared to that in the control group.

The effect of feed restriction on the average daily feed intake of broiler chickens is illustrated in Table 3. In T2 and 3 feed intakes was significantly lower than in birds fed ad libitum at week 4. After one week of feed restriction from $21-28$ days T2 birds totally compensated, feed intake was high on day 35 . At week 5, T3 groups had significantly reduced feed intake than T1 \& 2 after the duration of feed restriction period. On day 42 there was no difference $(P>0.05)$ in average daily feed intake for $\mathrm{T} 1$ and 2 , with $\mathrm{T} 3$ having the highest $(\mathrm{P}<0.05)$ feed intake. The highest feed intake can be related to the hypertrophy of the gastrointestinal tract that occurs after the restriction period when the birds are fed ad libitum. The observations observed in the present study partially agree with other researchers [25] [26] [27] which concluded that feed restriction increases feed intake.

The effect of feed restriction on the average daily feed intake of broiler chickens is illustrated in Table 4. In T2 and 3 feed intakes were significantly lower than in birds fed ad libitum at week 4. After one week of feed restriction from 21 
- 28 days T2 birds totally compensated, feed intake was high on day 35 . At week 5 , T3 groups had significantly reduced feed intake than T1 \& 2 after the duration of feed restriction period. On day 42 there was no difference $(\mathrm{P}>0.05)$ in average daily feed intake for T1 and 2 , with T3 having the highest $(\mathrm{P}<0.05)$ feed intake. The highest feed intake can be related to the hypertrophy of the gastrointestinal tract that occurs after the restriction period when the birds are fed ad $1 i$ bitum. The observations observed in the present study partially agree with other researchers [25] [26] [27] which concluded that feed restriction increases feed intake.

The effect of quantitative feed restriction on carcass characteristics of broiler chicken is presented in Table 5. The carcass weight of broilers was found to be higher $(\mathrm{P}<0.05)$ in T1 followed by T2 with T3 group having significantly lower carcass weights. The dressing percentage was found to be highest T2 group, although there was no significant differential effect on slaughter weight between

Table 4. Least square means and standard errors for average daily feed intake average daily gain subjected to control, one week and two weeks of feed restriction treatments at different stages of their growth.

\begin{tabular}{cccc}
\hline & \multicolumn{3}{c}{ Treatments (T) } \\
\cline { 2 - 4 } ADFI in weeks (ADFI W) & $\begin{array}{c}\mathrm{T} 1 \\
\text { (Control) }\end{array}$ & $\begin{array}{c}\mathrm{T} 2 \\
\text { (One week) }\end{array}$ & $\begin{array}{c}\text { T3 } \\
\text { (Two weeks) }\end{array}$ \\
\cline { 2 - 4 } & $152.5^{\mathrm{c}} \pm 5.18$ & $118.0^{\mathrm{b}} \pm 5.18$ & $107.3^{\mathrm{a}} \pm 5.18$ \\
ADFI W4 (g/bird/day) & $164.8^{\mathrm{b}} \pm 2.69$ & $165.9^{\mathrm{b}} \pm 2.69$ & $117.3^{\mathrm{a}} \pm 2.69$ \\
ADFI W5 (g/bird/day) & $183.8^{\mathrm{a}} \pm 1.86$ & $183.1^{\mathrm{a}} \pm 1.86$ & $186.3^{\mathrm{b}} \pm 1.86$ \\
\hline
\end{tabular}

Means in the same row with different superscripts are significantly different $(\mathrm{P}<0.05)$ from each other.

Table 5. Least square means and standard errors of dressing percentage and organ weights as proportions of live weights, subjected to control, one week and two weeks of feed restriction treatments from week three until six weeks of age.

\begin{tabular}{cccc}
\hline & \multicolumn{3}{c}{ Treatments (T) } \\
\cline { 2 - 4 } Carcass characteristics (kg) & $\begin{array}{c}\mathrm{T} 1 \\
\text { (Control) }\end{array}$ & $\begin{array}{c}\mathrm{T} 2 \\
\text { (One week) }\end{array}$ & $\begin{array}{c}\text { T3 } \\
\text { (Two weeks) }\end{array}$ \\
\hline Dressing percentage & $57.4 \pm 4.67$ & $55.7 .4 \pm 4.59$ & $60.9 \pm 4.75$ \\
Slaughter Weight & $87.1^{\mathrm{b}} \pm 4.67$ & $57.6^{\mathrm{a}} \pm 4.67$ & $53.4^{\mathrm{a}} \pm 4.67$ \\
Carcass Weight & $78.5^{\mathrm{b}} \pm 4.67$ & $102.9^{\mathrm{c}} \pm 4.67$ & $36.0^{\mathrm{a}} \pm 5.11$ \\
Organ weight as proportion of live weight & & & \\
Liver Weight & $0.017 \pm 0.001$ & $0.017 \pm 0.001$ & $0.018 \pm 0.001$ \\
Heart Weight & $0.004 \pm 0.002$ & $0.004 \pm 0.002$ & $0.004 \pm 0.001$ \\
Gizzard Weight & $0.024 \pm 0.001$ & $0.026 \pm 0.001$ & $0.025 \pm 0.001$ \\
Intestine Weight & $0.020^{\mathrm{a}} \pm 0.001$ & $0.026^{\mathrm{b}} \pm 0.001$ & $0.026^{\mathrm{b}} \pm 0.001$ \\
Feet Weight & $0.036 \pm 0.002$ & $0.038 \pm 0.002$ & $0.040 \pm 0.002$ \\
Head Weight & $0.026 \pm 0.001$ & $0.027 \pm 0.001$ & $0.02 \pm 0.001$
\end{tabular}

Means in the same row with different superscripts are significantly different $(\mathrm{P}<0.05)$ from each other. 
ad libitum and one-week restriction of broilers. These results contradict with [28] who found that feed restriction had no effect on the dressing percentage of broiler chickens. There was no significant effect $(P>0.05)$ on the relative weights of the heart, liver, gizzard, feet and heads among the treatment groups except for intestine weight which was lower $(\mathrm{P}<0.05)$ in $\mathrm{T} 1$ than $\mathrm{T} 2$ and 3 which were under restriction. This may be caused by an increase in feed conversion ratio in restricted broilers. [29] also observed a higher relative weight in restricted animals, compared with birds at ad libitum. The results are in accordance with observations by [30] and [31] who found no significant difference in relative weights of the liver at slaughter due to feeding regimes. [28] also found no significant difference in gizzard weight and heart.

\section{Conclusion}

Feed restriction had an effect on the growth performance of broiler chicken. Furthermore, the weight gained by the birds in unrestricted feeding was similar to the broilers that were restricted for one week. The broilers that were restricted for two weeks were not able to compensate and reach the slaughter weight when compared to the other treatments. The feed conversion efficiency was highest at week 5 for one-week restricted birds, which is why there was a high average daily gain. The ADG for the one-week restriction was high at week 5, after one week of feed restriction period and similarly, ADG for two weeks' restriction was high in week 6 after one week of feed restriction although it did not reach the same slaughter weight as other treatments. Feed restriction had minimal effect on the organ weights of broiler chickens, while intestines were affected by the restriction. The study showed that one-week restriction bird had better results compared to two weeks of restricted birds. Therefore, feed restriction for one week may be suitable for the growth performance of broiler chickens.

\section{Acknowledgements}

The authors are grateful to the DST-NRF Risk and Vulnerability Science Centre (RVSC) for funding this study.

\section{Authors' Contributions}

Z. G. \& D. C. planned and drafted the study. Z. G. collected and captured the data. Z. G. \& S. G. wrote the manuscript. L. Z. assisted with the planning and drafting of the manuscript. S. G. provided valuable scientific, technical inputs on the drafting and writing of the manuscript, critical review of the manuscript and data analysis. All authors read and approved the final manuscript.

\section{Conflicts of Interest}

All authors declare that there is no actual or potential conflict of interest between the authors and the other people or organizations that could inappropriately bias their work. 


\section{References}

[1] Aggrey, S.E., Karnuah, A.B., Sebastian, B. and Anthony, N.B. (2010) Genetic Properties of Feed Efficiency Parameters in Meat-Type Chickens. Genetics Selection Evolution, 42, 25. https://doi.org/10.1186/1297-9686-42-25

[2] Proudfoot, F.G., Hulan, H.W. and McRae, K.B. (1983) Effect of Feeding Poultry Diets Supplemented with Rapeseed Meal as a Primary Protein Source to Junvenile and Adult Meat Genotypes. Canadian Journal of Animal Sciences, 63, 957-965. https://doi.org/10.4141/cjas83-110

[3] Govaerts, T., Room. G. and Buyse, J. (2000) Early and Temporary Quantitative Food Restriction of Broiler Chickens, British Poultry Science, 41, 355-362. https://doi.org/10.1080/713654923

[4] Savory, C.J., Maros, K. and Rutter, S.M. (1993) Assessment of Hunger in Growing Broiler Breeders in Relation to a Commercial Restricted Feeding Programme Animal. Animal Welfare, 2, 131-152.

[5] Gross, W.B. and Siegel, P.B. (1982) Socialization as a Factor to Resistance to Infection, Feed Efficiency, and Response to Antigen in Chickens, American Journal of Veterinary Research, 43, 20010-20012.

[6] Wilson, P.N. and Osbourne, D.F. (1960) Compensatory Growth after Undernutrition in Mammals and Birds. Biological Review, 35, 324-363.

https://doi.org/10.1111/j.1469-185X.1960.tb01327.x

[7] Ryan, W.J. (1990) Compensatory Growth in Cattle and Sheep. Nutrition Abstract and Review, 60, 653-664.

[8] Zubair, A.K. and Leeson, S. (1996) Compensatory Growth in the Broiler Chicken: A Review. World s Poultry Science Journal, 52, 189-201. https://doi.org/10.1079/WPS19960015

[9] Ledin, I. (1984a) Effect of Restricted Feeding and Realimentation on Growth, Carcass Composition and Organ Growth during the First Seven Days of Realimentation in Rabbit. Acta Agriculturae Scandinavica, 34, 54-66. https://doi.org/10.1080/00015128409436181

[10] Ledin, I. (1984b) A Note on the Effect of Different Feeding Levels on the Rate of Digesta Passage in Rabbits. Acta Agriculturae Scandinavica, 34, 67-70. https://doi.org/10.1080/00015128409436182

[11] Statistical Analysis Systems (2003) SAS User's Guide. SAS Institute Inc., Cary.

[12] Newcombe, M., Fitz-Coy, S.H. and Harter-Dennis, J.M. (1992) The Effect of Feed Restriction and Eimeria Maxima Infection with or without Medication on Growth and Feed Intake in Broilers. Poultry Science, 71, 1442-1449. https://doi.org/10.3382/ps.0711442

[13] Palo, P.E., Sell, J.L., Piguer, F.J, Soto-Salanova, M.F. and Vilaseca, L. (1995) Effect of Early Nutrient Restriction on Broiler Chickens. 1. Performance and Development of the Gastrointestinal Tract. Poultry Science, 74, 88-101.

https://doi.org/10.3382/ps.0740088

[14] Fontana, E.A., Weaver, W.D., Watkins, B.A. and Denbow, D.M. (1992) Effect of Early Feed Restriction on Growth, Feed Conversion, and Mortality in Broiler Chickens. Poultry Science, 71, 1296-1305. https://doi.org/10.3382/ps.0711296

[15] Khetani, T.L., Nkukwana, T.T., Chimonyo, M. and Muchenje, V. (2008) Effect of Quantitative Feed Restriction on Broiler Performance. Tropical Animal Health and Production, 41, 379-384. https://doi.org/10.1007/s11250-008-9200-Z

[16] Zubair, A.K. and Leeson, S. (1994) Effect of Varying Period of Early Nutrient Restriction on Growth Compensation and Carcass Characteristics of Male Broilers. 
Poultry Science, 73, 129-136. https://doi.org/10.3382/ps.0730129

[17] Plavnik, I. and Hurwitz, S. (1991) Response of Broiler Chickens and Turkey Poultry to Feed Restriction of Varied Severity during Early Life. British Poultry Science, 32, 343-352. https://doi.org/10.1080/00071669108417359

[18] Hurwitz, S., Weiselberg, M., Eisner, U., Bartov, I., Riesenfeld, G., Sharvit, M., Niv, A. and Bomstein, S. (1980b) The Energy Requirements and Performance of Growing Chickens and Turkeys as Affected by Environmental Temperature. Poultry Science, 59, 2290-2299. https://doi.org/10.3382/ps.0592290

[19] Mazzuco, H., Guidoni, A.L. and Jaenisch, F.R. (2000) Effect of Qualitative Feed Restriction on Compensatory Growth in the Broiler Chicken. Pesquisa Agropecuaria Brasileira, 35, 543-549. https://doi.org/10.1590/S0100-204X2000000300009

[20] Yu, M.U., Robinson, E.F., Clandinin, M.T. and Bodnar, L. (1990) Growth and Body Composition of Broiler Chickens in Response to Different Regimens of Feed Restriction. Poultry Science, 69, 2074-2081. https://doi.org/10.3382/ps.0692074

[21] Fattori, T.R., Wilson, H.R., Harms, R.H. and Miles, R.D. (1991) Response of Broiler Breeder Females to Feed Restriction below Recommended Levels. 1. Growth and Reproductive Performance. Poultry Science, 70, 26-36. https://doi.org/10.3382/ps.0700026

[22] Lee, K.H. and Leeson, S. (2001) Performance of Broilers Fed Limited Quantities of Feed or Nutrients during Seven to Fourteen Days of Age. Poultry Science, 80, 446-454. https://doi.org/10.1093/ps/80.4.446

[23] Urdaneta-Rincon, M. and Leeson, S. (2002) Quantitative and Qualitative Feed Restriction on Growth Characteristics of Male Broiler Chickens. Poultry Science, 81, 679-688. https://doi.org/10.1093/ps/81.5.679

[24] Yu, M.W., Robinson, F.E. and Robblee, A.R. (1992) Effect of Feed Allowance during Rearing and Breeding on Female Broiler Breeders. 1. Growth and Carcass Characteristics. Poultry Science, 71, 1739-1749. https://doi.org/10.3382/ps.0711739

[25] Zhan, X.A., Wang, M., Ren, H., Zhao, R.Q., Li, J.X. and Tan, Z.L. (2007) Effect of Early Feed Restriction on Metabolic Programming and Compensatory Growth in Broiler Chickens. Poultry Science, 86, 654-660. https://doi.org/10.1093/ps/86.4.654

[26] Cabel, M.C. and Waldroup, P.W. (1990) Effect of Different Nutrient Restriction Programs Early in Life on Broiler Performance and Abdominal Fat Content. Poultry Science, 69, 652-660. https://doi.org/10.3382/ps.0690652

[27] Sahraei, M. and Shariatmadari, F. (2007) Effect of Different Levels of Diet Dilution during Finisher Period on Broiler Chicken's Performance and Carcass Characteristics. Poultry Science, 6, 280-282. https://doi.org/10.3923/ijps.2007.280.282

[28] Mahmood, S., Mehmood, S., Ahmad, F., Masood, A. and Kausar, R. (2007) Effect of Feed Restriction during Starter Phase on Subsequent Growth Performance, Dressing Percentage, Relative Organ Weights and Immune Response of Broilers. Pakistan Veterinary Journal, 27, 137-141.

[29] Tolkamp, B.J., Sandilands, V. and Kyriazakis, I. (2005) Effects of Qualitative Feed Restriction during Rearing on the Performance of Broiler Breeders during Rearing and Lay. Poultry Science, 84, 1286-1293. https://doi.org/10.1093/ps/84.8.1286

[30] Susbilla, P., Frankel, T.L., Parkinson, G. and Gow, C.B. (1994) Weight of Internal Organs and Carcass Yield of Early Food Restriction of Broilers. British Journal of Poultry Science, 35, 677-685. https://doi.org/10.1080/00071669408417734

[31] Jones, G.P.D. (1995) Manipulation of Organ Growth by Early-Life Food Restriction: Its Influence on the Development of Ascites in Broiler Chickens. British Poultry Science, 36, 135-142. https://doi.org/10.1080/00071669508417759 